\title{
High-speed rail as a solution to metropolitan passenger mobility: The case of Shenzhen-Dongguan-Huizhou metropolitan area
}

\author{
Xiongbin Lin (Corresponding Author) \\ Ningbo University \\ xiongbinlin@126.com
}

Ian MacLachlan

Peking University

maclachlan@uleth.ca

\author{
Jiawen Yang \\ Peking University \\ yangjw@pkusz.edu.cn
}

\begin{abstract}
High-speed rail (HSR) has played an important role in China's long-distance travel. However, the potential of this transport technology to meet the demand of passenger mobility at the metropolitan scale is still unclear. This research examines this potential by studying transportation investment for intercity passenger mobility in the Shenzhen-Dongguan-Huizhou Metropolitan Area, where multiple fixed guideway transit systems have been proposed and HSR service has been implemented to carry passengers between central Shenzhen and outer portions of this metropolitan region. Comparison of alternative modes explains why HSR is competitive at the metropolitan scale. Interviews with relevant stakeholders reveal the institutional conditions for utilizing the national HSR system for regional passenger mobility.
\end{abstract}

Keywords: High-speed rail, metropolitan area, passenger mobility, China

\section{$1 \quad$ Introduction}

Fixed guideway transit services have been recommended to improve passenger mobility in high-density metropolitan areas, mainly because of their relatively high speed, travel time reliability and potential to substitute for automobile trips (Cervero, 2013; Diao, Zhu, \& Zhu, 2017; Fan, Guthrie, \& Levinson, 2012; Wang, 2011). In China, rail transit systems are built not only for passenger trips within the administrative boundaries of big cities, but also those trips linking neighboring cities ( $\mathrm{Li}$, Luan, Yang, \& Lin, 2013; Xu \& Yeh, 2013; Yang, Lin, \& Xie, 2015). Those systems range from standard metro systems to passenger services operated by the national railway corporation (Wang, Rong, Xu, \& Sui, 2012; Zhou, 2016). For example, by the end of 2017, 34 cities in mainland China had fixed guideway transit in operation, with a total track length of over 5,000 kilometers (China Association of Metros, 2018). The Yangtze River Delta, Pearl River Delta (PRD), and Capital Economic Zone have each pro-

Copyright 2018 Xiongbin Lin, Jiawen Yang \& Ian MacLachlan

http://dx.doi.org/10.5198/jtlu.2018.1297

ISSN: 1938-7849 | Licensed under the Creative Commons Attribution - Noncommercial License 4.0

The Journal of Transport and Land Use is the official journal of the World Society for Transport and Land Use (WSTLUR) and is published and sponsored by the University of Minnesota Center for Transportation Studies.

\section{Article history:}

August 1, 2018

Accepted: September 17, 2018

Available online: December 6, 2018 
duced their own regional rail system plans to meet the increasing demand for passenger services (State Council of China, 2005).

Underpinning this progress is China's continuous emphasis on fixed guideway transportation systems for integrated regional mobility. For example, in December 2015, China's National Development and Reform Commission (NDRC) and Ministry of Transport (MOT) jointly released the Comprehensive Transport Network Plan for Urbanized Regions, which advocated closely linked megaregions by providing multimodal intercity transport services. It proposed that by the end of 2020, intercity railway networks will be established within the Capital Economic Zone, Yangtze River Delta, and Pearl River Delta, China's top three megaregions. A "one-hour commuting radius" from the core city to outer portions of each megaregion is the policy target.

As urbanization continues and metropolitan area boundaries expand outward, a preference for higher speed naturally emerges. In the United States, commuter rail is the major format of fixed guideway transit that carries passengers between the central city and its outer suburbs (Armstrong \& Rodríguez, 2006). Similarly, China is developing its own version of commuter rail. For example, the intercity rail system in the PRD to some extent serves the role of commuter rail (Li et al., 2013; Yang et al., 2015; Li et al., 2018). More recently, the high-speed rail system, which was built and operated by the National Railway Corporation for long-distance passenger trips, has become a desirable choice for local governments, because of both its high speed and the pre-existing infrastructure built by the national government. However, the utilization of this national system for regional passenger mobility is still quite rare in China. The first notable example did not arrive until September 2015, when Shenzhen's Pingshan Express began operation. The service was extended to link Huizhou and Shanwei in January 2017. It uses the tracks and stations of the Xiamen-Shenzhen HSR, which is a portion of the national HSR network.

This HSR-based regional express service was selected as one of China's model commuter rail services by China NDRC in 2017. More HSR-based intercity express services are likely to follow in other regions. Therefore, it is essential to understand 1) why local governments selected HSR and; 2) what conditions are necessary to adapt national HSR for regional passenger mobility. This paper offers answers to these questions by studying relevant transport investment actions in the Shenzhen-DongguanHuizhou Metropolitan Area (SGHMA). The main objectives of this study are to: 1) reveal the events leading to this new service, 2) assess its competitive advantage over other options, and 3) identify the institutional factors necessary to operate such HSR service for metropolitan passengers.

\section{Regional transportation context}

SGHMA is located in China's Guangdong Province. The majority of SGHMA is within the Pearl River Delta, one of the most highly urbanized regions in China. The PRD region has an area of about 40,000 square kilometers and includes nine cities: Guangzhou, Shenzhen, Dongguan, Foshan, Huizhou, Zhongshan, Zhuhai, and Zhaoqing. By the end of 2015, the PRD had a total population of 56.16 million and a total GDP of $¥ 6.23$ trillion (about US\$ 918 billion). After the release of the Guangdong Government's Outline for the Reform and Development of the Pearl River Delta in 2008, three metropolitan areas were officially defined within the PRD: Guangzhou-Foshan-Zhaoqing (GFZ), the ZhongshanJiangmen-Zhuhai (ZJZ), and the Shenzhen-Dongguan-Huizhou (SGH) (Guangdong Government, 2008). In accordance with the Guangdong New-type Urbanization Plan released in 2016, Shanwei City and Heyuan City were added to expand the eastern margin of SGHMA (Figure 1). Despite being administratively separated, these cities are quite willing to collaborate on regional issues such as transportation and economic development. The need to cooperate in the supply of high-speed passenger transportation services in this region is driven mainly by two forces: spiraling housing prices and industrial decentralization. 

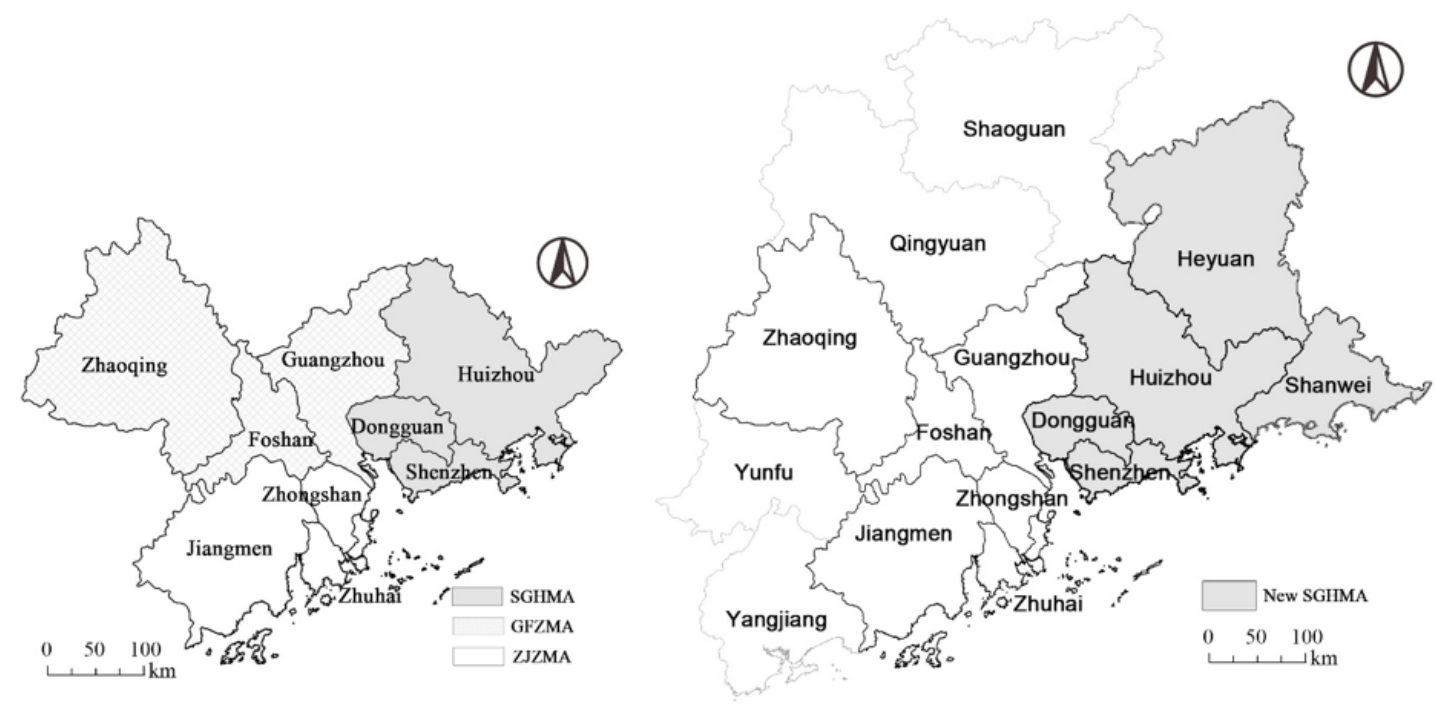

Figure 1: Three expanding metropolitan areas in the PRD Region (2008 and 2016)

First, housing has become unaffordable for many people in central Shenzhen, which leads to lengthened commuting trips as residents move outward for affordable housing. For example, the average housing price in Shenzhen has experienced tremendous growth since 2014. At present, the average housing price in Shenzhen is more than $¥ 50,000$ per square meter, almost 5 times higher than Huizhou. In addition, the average cost for an apartment is approximately $¥ 5.5$ million. According to a survey conducted in 2016, over 92\% of the respondents think Shenzhen's housing price is too high and $60 \%$ of them would be willing to buy a unit in neighboring Huizhou, Dongguan, or Zhongshan (Tencent News, 2016).

Second, passenger trips have been lengthened by the relocation of business activities from central Shenzhen to the outskirts of SGHMA. Intercity collaboration in economic development has long been encouraged in PRD. For example, the Guangdong Government's Decision on Promoting the Relocating of Industry and Labor issued in 2008, encouraged "unified development" among cities in the PRD area and beyond. The provincial government initiated plans, regulations, and policy measures to encourage the creation of industrial parks and accommodate relocated businesses. As the leading economic power house in this region, Shenzhen faces a tight land supply. Many enterprises have moved out of Shenzhen to Huizhou or other cities where land prices and production costs are lower. In 2015, for example, among the 300 manufacturing projects (with a total investment of $¥ 23.15$ billion) settled in Huiyang District in Huizhou City, 213 came from Shenzhen (Huizhou News, 2016).

As a result, the volume of intercity passenger trips in the metropolitan area is increasing significantly throughout the PRD. For example, a report released by Didi Chuxing (2017) indicated that intercity passenger trips in the PRD in 2017 were triple that of 2016.

\section{The HSR option for intercity passenger mobility}

Several options could accommodate the increased number of lengthened trips, including intercity bus services (Geloso, 2012), intercity metro systems (Yang et al., 2015; Li et al., 2018), commuter rail services (Armstrong \& Rodríguez, 2006; Deka, 2012), long-distance regular trains with local stops, or intercity high speed trains (Sperry, Ball, \& Morgan, 2011; Charles, Ryan, \& Kivits, 2012; Mu, De Jong, 
Ma, \& Xi, 2015; Diao et al., 2017; Xu, 2017). For example, Shanghai Metro Line 11 (linking Shanghai Disney Resort and Suzhou Huaqiao) and Guangzhou-Foshan Metro, are examples of intercity metros built through the collaboration of neighboring cities (Lin, Yang, \& Wang, 2017).

High-speed trains naturally attract more attention because of their time-saving potential. Figure 2 shows all HSR-based services that could be used for regional passenger trips in the PRD. The dashed lines belong to the national HSR system and are managed by its local branch - Guangzhou Rail. The relevant trains mainly serve long-distance trips. The line-haul speed could go beyond $300 \mathrm{~km} /$ hour and they have stops within each municipality, but the service frequency and schedule do not meet the needs of metropolitan commuters. For example, the departure and arrival time of those trains may not match the peak commuting hours, when most trips within the metropolitan area actually take place. Each train sells only a small percentage of seats for trips falling within PRD, as the principal objective is to serve long-distance trips. The cost of arriving late and missing the scheduled train is high. One can only ride the train printed on the ticket and a passenger who misses the train must go to the ticket booth, request a partial refund, and buy a new ticket. This whole process is exasperating, time-consuming and cumbersome for daily travelers within the metropolitan area who typically require much more schedule flexibility.

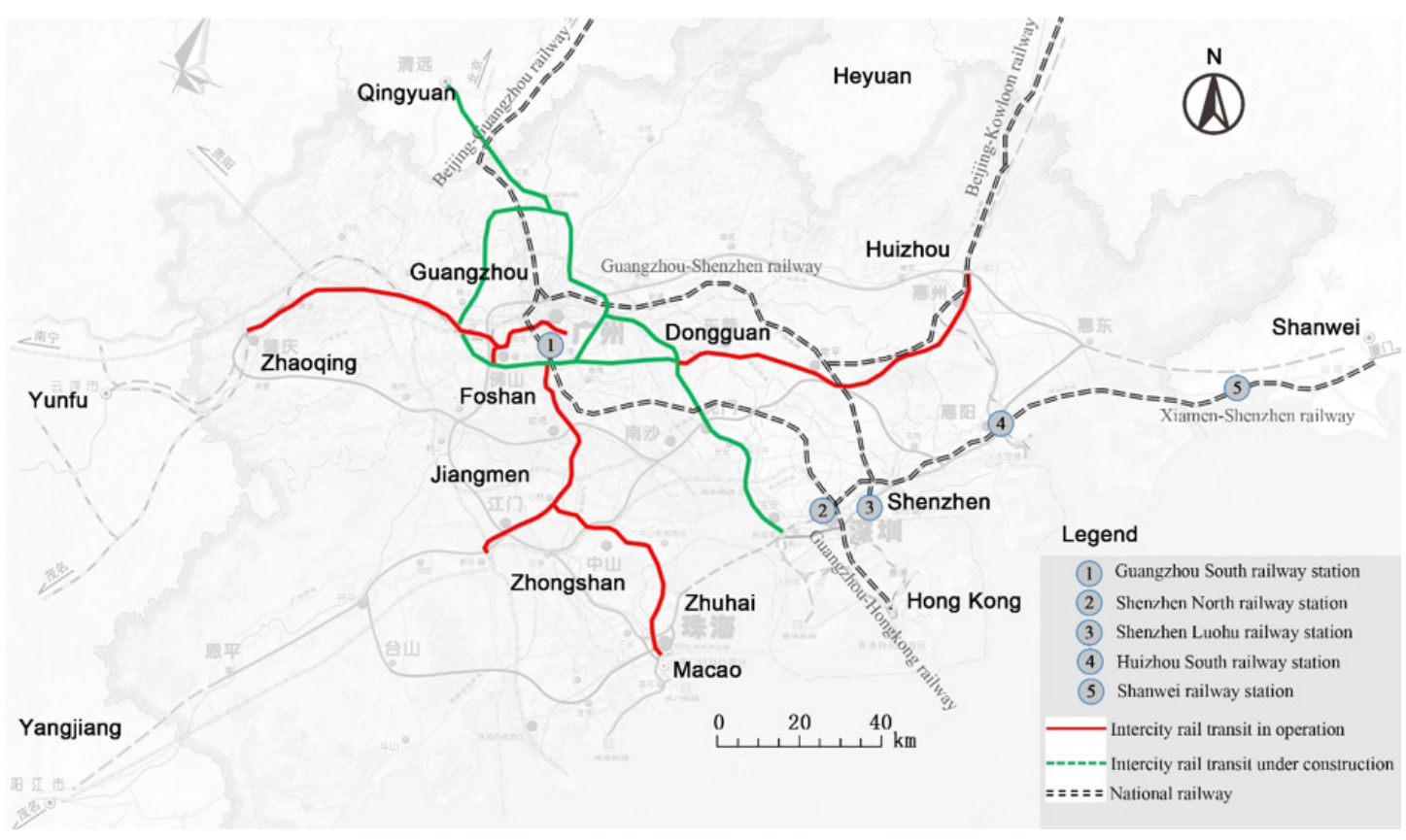

Figure 2: Intercity rail services in the Pearl River Delta region

Source: Compiled by authors from web-based news releases from China Railway and Guangdong provincial government

As a response to these issues, the Guangdong provincial government began to work with the Ministry of Railways for a regional system in 2005: the PRD intercity rail system (Guangdong Government, 2005). The system was planned to have a track length of over 2,000 km and by 2018 a number of intercity rail routes were already in operation (Figure 2). The first line links Guangzhou and Zhuhai. Its operation began in 2011. For now, the Guangzhou-Foshan and Dongguan-Huizhou intercity rail lines are also in operation (red lines in Figure 2). In addition, the intercity rail line of Guangzhou-Qingyuan, the line of Guangzhou-Dongguan-Shenzhen, and the Loop Line of Guangzhou-Foshan are under construction (green lines in Figure 2). This intercity rail system is jointly funded by the Guangdong provincial government and relevant city governments (Xu \& Yeh, 2013; Li et al., 2013). The service uses 
Chinas earlier version of the harmonic train ("D trains") with a line-haul speed purposely set below 200 $\mathrm{km} /$ hour. It is not really HSR, but close to it. The operational format is a hybrid of the national HSR service and local transit service. The services are still operated by Guangzhou Rail, even though they are funded by both the provincial and municipal governments. Access to and exit from train stations is similar to traditional train services, rather than the jump-on jump-off convenience of a street-corner metro station. However, there has been an effort to make it more convenient for intraurban trips. The schedule constraint is relaxed. The rider can board the first-available train rather than the train specified on the ticket, always subject to seat availability, of course. The schedule and frequency are now structured to match the local peak commuter demand and all seats are available for regional trips.

This system has not yet been completed, and for three reasons, it now appears unlikely that it ever will. First, the newest generation of HSR can easily run around $300 \mathrm{~km} /$ hour, much faster than PRD intercity services. Second, the central government has decided to densify the HSR network, particularly in the most developed coastal regions. Some corridors previously planned for intercity routes are now shared with the national HSR. Competition between the two systems should be avoided. Third, the national HSR system is fully funded by the central government. The provincial and municipal governments have no strong reason to continue to invest in this intercity rail transit system, as long as the HSR infrastructure can be used to run the desired intraurban service.

Indeed, the use of HSR infrastructure for regional passenger mobility was pioneered in the PRD region. The Shenzhen-Huizhou-Shanwei intercity HSR (hereafter abbreviated as Shenshan Express) uses the infrastructure of the Xiamen-Shenzhen Railway (from Shenzhen to Xiamen), which is a part of the national HSR system (Figure 3). The service started as the Shenzhen Pingshan Express in September 2015, and later was extended to Shanwei in January 2017. The city governments linked by the Shenshan Express contracted with Guangzhou Rail to operate this intercity service. How has this new approach emerged? What is the policy implication? A detailed study of this case should reveal the far reaching impact of HSR for regional passenger mobility in China.

\section{Regional HSR service in the Shenzhen-Pingshan-Huizhou-Shanwei corridor}

The Shenshan Express originates at Futian Station in central Shenzhen and ends at Shanwei Station in Shanwei City on the eastern margin of the metropolitan area, a distance of 150 kilometers. The Shenshan Express dispatches 14 pairs of trains every day, with a headway of less than one hour. The earliest train leaves Shenzhen for Shanwei at 6:55 a.m. and the full trip takes about 70 minutes.

While one end of this corridor is the prosperous commercial and financial district of central Shenzhen, the other end is anchored by the Shenzhen-Shanwei Cooperation Zone (SSCZ), which is the prime example of industrial decentralization and relocation in this region (Figure 3). Shanwei City is relatively far from the core of the PRD. Government leadership has been eager to attract Shenzhen's overflowing economic activities. In 2009, Shenzhen (Shanwei) Industrial Park, the early version of the SSCZ, was established in Shanwei in February 2011, after the release of the Guangdong Provincial Government's approval of the Institutional Framework of the SSCZ. Later, the industrial park was expanded to attract more businesses from Shenzhen. Today, the SSCZ covers a land area of 468 square kilometers with a planned total resident population of 71,000. The relocated businesses from Shenzhen of course still maintain close ties with Shenzhen, which produces many trips between Shenzhen and Shanwei. 


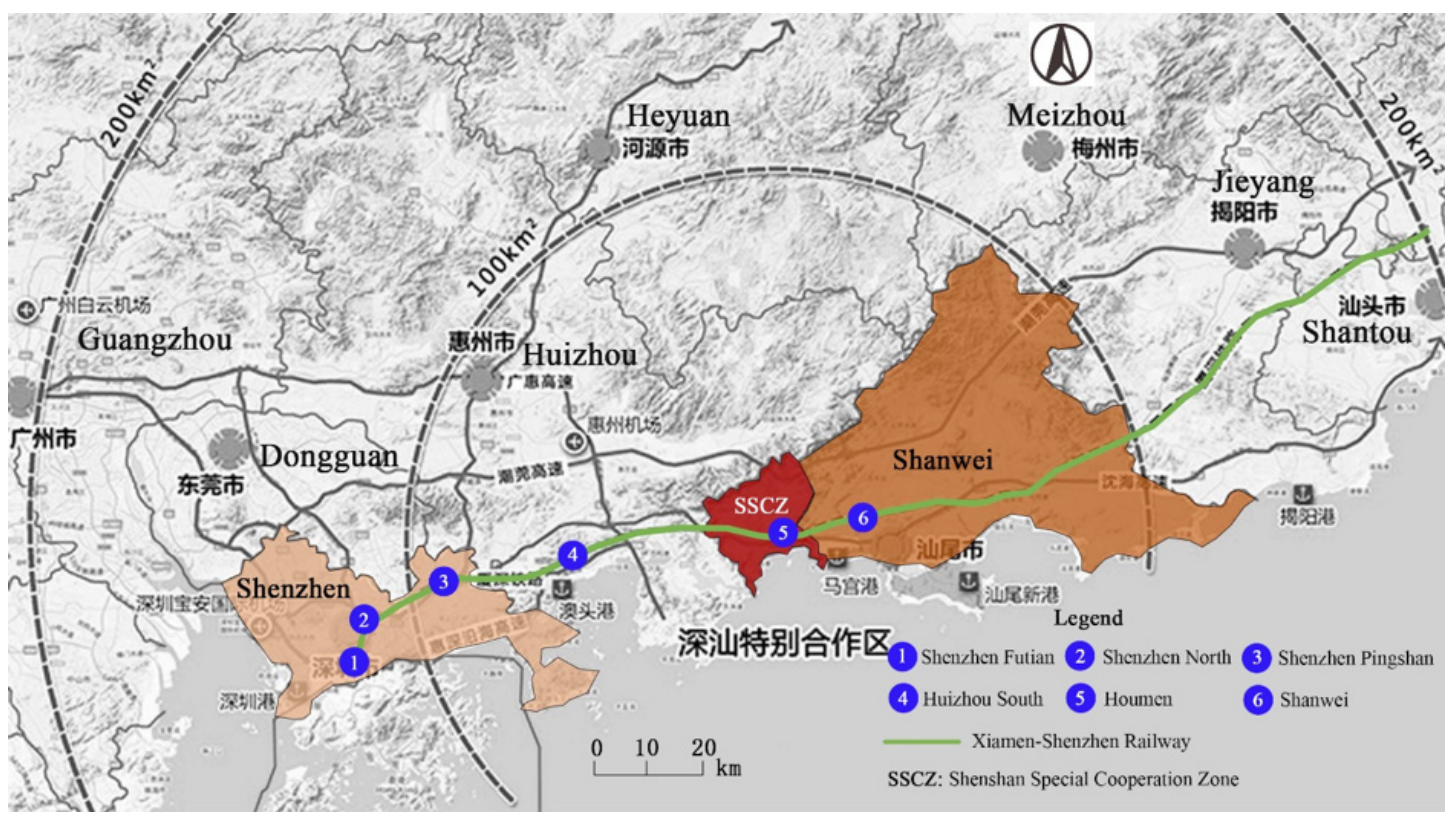

Figure 3: Shenzhen-Huizhou-Shanwei intercity HSR

Source: Compiled by authors based on Shenzhen-Shanwei Cooperation Zone Plan, 2010

While media releases have covered the general features of this service, we have interviewed the key informants who participated in the creation of this service. They include government officials and city planners who engaged in proposing and advancing Shenshan Express, as well as a few transport experts who work for planning firms or universities (Table 1).

Table 1: Major interviews with relevant stakeholders and experts

\begin{tabular}{|c|c|c|c|}
\hline No. & Interviewee & Interview date & Interview venue \\
\hline 1 & $\begin{array}{r}\text { Mr. R, senior city planner in Beijing; expert in } \\
\text { national railway planning }\end{array}$ & 2018.4 & WeChat interview \\
\hline 2 & $\begin{array}{l}\text { Mr. D, manager of Shenzhen Pingshan Transport } \\
\text { Development Office; key proponent of Shenshan } \\
\text { Express }\end{array}$ & 2018.4 & $\begin{array}{c}\text { Face-to-face interview in } \\
\text { Pingshan Shenzhen }\end{array}$ \\
\hline 3 & Mr. Y, senior city planner in Shenzhen; chief planner \\
for Shenshan Express & 2018.4 & $\begin{array}{c}\text { Face-to-face interview in } \\
\text { Futian Shenzhen }\end{array}$ \\
\hline 5 & $\begin{array}{c}\text { Mr. Z, manager in Guangdong Railway Develop- } \\
\text { ment Group; experts in PRD intercity rail }\end{array}$ & $\begin{array}{l}2018.3(1) \\
2018.4(2)\end{array}$ & $\begin{array}{c}\text { Telephone interview and } \\
\text { face-to-face interview in } \\
\text { Guangzhou }\end{array}$ \\
\hline & Mr. L, professor in Beijing Jiaotong University; & $2018.3(1)$ & $\begin{array}{c}\text { Telephone interview and } \\
\text { face-to-face interview in } \\
\text { Shenzhen }\end{array}$ \\
\hline
\end{tabular}




\subsection{The Shenzhen Pingshan Express}

The service first emerged from the Shenzhen city government's effort to strengthen its transport connection with its suburban Pingshan District. Transport demand between central Shenzhen and its peripheral areas has been growing rapidly as a result of the housing affordability and industrial relocation issues discussed above. The distance from central Pingshan to central Shenzhen is about 50 kilometers, which makes bus and metro uncompetitive for commuting purposes. High-speed rail naturally became an option. Pingshan indeed has an HSR station on the Xiamen-Shenzhen HSR. Construction of this HSR started in 2007 and began operation in late 2013. However, this service mainly serves long-distance trips, rather than the daily regional trips to and from central Shenzhen.

The potential use of HSR infrastructure for intraurban trips was considered earlier than the operation of Xiamen-Shenzhen Railway; Pingshan District Government negotiated with the regional branch of China Railway-Guangzhou Rail, on the possibility of operating the Pingshan Express on the Xiamen-Shenzhen Railway track. However, the proposal was not successful. First, there was no clear national regulation and no precedent to guide this proposal. Interviewee No. 1, with more than ten years of professional experience in national railway planning, observed the lack of formalized guidance to implement a regional service on the national railway system, and he pointed out,

Currently, the central government has no clear guidance on whether or how the national HSR can be used for regional service. Therefore, local governments have to negotiate a proposal with China Railway and its regional branch, which is subject to uncertainty. Of course, if the operating schedule and cost-sharing arrangements are workable, the local branch may agree to operate the regional service

Second, the objective of Guangzhou Rail differs significantly from local governments. Guangzhou Rail focuses on long distance trips. The operation of the Shenzhen Pingshan Express would absorb some operational capacity and reduce the future opportunity for Guangzhou Rail to add long distance service. Third, the business model proposed by the local government did not make much sense at that time. Shenzhen City Government proposed to rent the HSR track. The idea was for the local government to buy its own trains, construct its own platforms, and operate its own service. According to Interviewee No. 2:

We began to envisage the operation of HSR service from Pingshan to Shenzhen North in 2012 when the Xiamen-Shenzhen Railway was still under construction. ... But the proposal had been delayed because of the lack of an effective business model. ... This initiative was substantially pushed forward when the concept of service purchase was introduced and strong support from higher level governments was expressed.

This track renting model would add operational complexity for Shenzhen-Xiamen railway. Guangzhou Rail politely turned down this proposal, arguing that passenger travel demand between Pingshan and central Shenzhen was still low and that the seats allocated to this route segment were still sufficient. The turning point arrived when the concept of service purchase was put on the table in August 2015, when Xingrui MA was installed as the new Party Secretary for Shenzhen. He is not only the head of Shenzhen City Government, but also a member of the Standing Committee of the Communist Party of China. With this level of political influence, he was able to bring Guangzhou Rail to the table together with the other stakeholders, including Pingshan District Government, Shenzhen Metro, Shenzhen Bureau of Planning, and Bureau of Transport. As Interviewee No. 4 observed: 
Shenzhen City Government released the Eastern Shenzhen Rising Strategy (Shenzhen dongjin) in 2015, and the Party Secretary Xingrui MA attached great importance to the development of Pingshan District. In a visit to Pingshan District, MA emphasized the significance of Pingshan Express.

As a result, the Pingshan District Government quickly signed an agreement with Guangzhou Rail on Pingshan Express. Based on this agreement, each pair of trains operating on the Pingshan HSR will receive an annual subsidy of $¥ 5$ million (Interviewee No. 3), which will be financed jointly by Shenzhen City Government and Pingshan District Government. With the introduction of the Pingshan Express in September 2015, the travel time from central Pingshan to central Shenzhen decreased from about two hours by bus and one hour by car to 20 minutes by rail. The daily ridership of the Pingshan Express reached 5,000 in 2015 soon after it began operation.

\subsection{The Shenshan Express}

The inauguration of the Pingshan Express excited the city governments of Huizhou and Shanwei, who are also on the Shenzhen-Xianmen HSR corridor, and they sensed the opportunity to extend the Pingshan Express into a Shenzhen-Huizhou-Shanwei Express (Figure 3). For a period of time, city governments in SGHMA have tried to connect with each other using a regional rail system. For example, the city governments involved have signed the Joint Conference Governing Regulation, which specified collective government actions in key regional transport plans and related capital projects. Several regional plans had already been jointly approved, including the Eastern Pearl River Delta Closer Partnership Framework Agreement, Planning Integration Partnership Agreement of Shenzhen-Dongguan-Huizhou Metropolitan Area, and Integrated Transport Planning of Shenzhen-Dongguan-Huizhou Metropolitan Area.

At the same time, the Shenzhen city government was also seeking a significant operational change because of its increasing role in administering the SSCZ. After a few years of joint administration of SSCZ by Shenzhen and Shanwei city governments, the Guangdong provincial government decided to grant Shenzhen City the sole administrative right to govern the SSCZ even though the territory is some $150 \mathrm{~km}$ distant. This administrative change was viewed as essential to the effective promotion of economic development in the SSCZ, with the expectation that more businesses would move from Shenzhen to SSCZ and that passenger trips between Shenzhen and SSCZ would increase further. A transportation service as fast as HSR becomes essential if SSCZ is to be effectively integrated with the territory of Shenzhen City. As Interviewee No. 2 put it:

The local governments (thus) worked together on a proposal to extend Pingshan Express further east. Benefiting from Shenzhen City Government's good connection with Guangzhou Rail and the established experience in operating Pingshan HSR, the proposal worked well with Guangzhou Rail.

The tricky part is the operational schedule and the sharing of the operating deficit among relevant local governments. There were no established precedent or accounting rules for such an intergovernmental partnership (Interviewee No. 5). The governments contracted with Shenzhen Transportation Research Center, China's biggest urban transportation consulting firm, to work out the details. They soon reached an agreement on an operating schedule and a subsidy formula. Huizhou, Shanwei, SSZC, and Pingshan District Governments cover 21\%, 19\%, 13\%, and $47 \%$ of the operating deficit respec- 
tively (Bendibao, 2016). The percentages were calculated based on the numbers of trains stopping and the train-kilometerage within each jurisdiction, according to Interviewee No. 3, the major negotiator of this deal.

The Shenshan Express began operation in January 2017, running from Shenzhen's Futian Station ${ }^{1}$ to Shanwei Station. This new service takes only 30 minutes from Shenzhen to Huizhou and 60 minutes to Shanwei. Those who book a ticket online can ride the Shenshan Express by swiping their identity cards, avoiding any paper ticket. They can ride the next available train; subject only to seat availability, they can ride an earlier or later train provided the passenger does not change the origin or destination. In 2017, the occupancy rate of the Shenshan express was over 40\%, exceeding expectations (Interviewee No. 3).

\section{Competitiveness of HSR express to serve regional trips}

Other options to enhance intra-metropolitan rail service have long been considered in SGHMA before the Pingshan Express became an option. In particular, there was an attempt to connect the Shenzhen and Huizhou metro systems. Early in 2006, when the Huizhou city government began to plan for a metro system, it approached Shenzhen city government to discuss the feasibility of connecting their two systems at the inter-municipal border. In 2008, a connection between Huizhou and Shenzhen metros was proposed in Huizhou Rail Transit Network Plan. In May 2012, Shenzhen, Huizhou, and Dongguan met to sign the Transportation System Integration Plan of the Shenzhen-Dongguan-Huizhou Metropolitan Area. The proposed connection of the Shenzhen and Huizhou Metros was a major issue at this meeting (Dongguan Daily, 2012). One year later, the Regional Coordinated Development Plan of the ShenzhenDongguan-Huizhou Metropolitan Area (2012-2020), as well as the Shenzhen-Huizhou Cooperation Memoranda of 2013 were jointly released (Dongguan Daily, 2013). These agreements highlight the feasibility of connecting metro systems of neighboring cities to meet regional mobility needs. Most recently, the construction of Shenzhen Metro Line 14, which is planned to link with Huizhou Metro Line 1, was begun in early 2018 (Sina News, 2018). However, Huizhou Metro Line 1 is still awaiting approval from NDRC. After more than a decade, none of the SGHMA metro lines have yet been articulated.

Several factors account for the delay of the Shenzhen-Huizhou metro connection. First, metro systems are generally solely funded and operated by city governments, with no subsidy from higher level governments. Under this budget constraint, a value-capture approach is generally utilized in China's metro planning. Metro alignment and station placement are strongly associated with the potential land-sector revenue for the local government (Yang, Chen, Le, \& Zhang, 2016). City governments are typically reluctant to extend metro lines to the city border where land prices (hence city government revenues) tend to be low. In the PRD, the Guangzhou-Foshan Metro is the only intercity metro system in operation. It was funded by Guangzhou City Government (51\% of cost) and Foshan City Government (49\% of cost). This intercity metro line was possible primarily because central Guangzhou and central Foshan are only 20 kilometers apart (Lin, Yang, \& Sun, 2015).

Second, city governments are concerned with the distributional effects of connected metro systems on revenues. Considering the huge gap in housing prices between Shenzhen and Huizhou, a connected regional metro system may lead a great number of Shenzhen residents to buy condos in Huizhou, which will lead to significant government revenue loss in Shenzhen's real estate sector.

${ }^{1}$ The original Pingshan Express ran between Shenzhen North Station and Pingshan Station. Three months after the introduction of the Pingshan Express, Shenzhen Futian HSR Station, which is directly below Shenzhen's city hall, was put in use. The service was extended from Shenzhen North Station to Futian Station when it was rebranded as Shenshan Express. 
Third, under current regulations, city governments' metro plans must be evaluated and approved by China NDRC. Intercity metro connection is always subject to more uncertainties, as it involves metro lines at the city outskirts where ridership tends to be low. By the criteria of ridership and operational revenue, those lines are less likely to be approved by NDRC as Interviewee No. 3 observed.

First, extending the Shenzhen metro to Huizhou may directly transfer development opportunities to Huizhou while the outskirts of Shenzhen are still waiting for development opportunities. Second, the NDRC is raising the threshold for local governments to construct metro systems. It still remains unknown whether and when the Huizhou metro plan will be approved by NDRC.

Indeed, in July 2018, the State Council of China (2018) updated the regulation on municipal rail transit planning and construction, which is more stringent than the pre-existing version of 2003 (State Council of China, 2003). The update increases the threshold city government’s GDP from $¥ 100$ billion to $¥ 300$ billion, and the threshold city government revenue from $¥ 10$ billion to $¥ 30$ billion. In addition, the required population size in the urban districts of each municipality increases from 1 million to 3 million. By this new standard, it is impossible for the Huizhou metro plan to be approved by the NDRC in the near future.

In contrast, it took only two years to move the idea of Pingshan Express into reality. Remarkably, after the Shenzhen government and Guangzhou Rail reached an agreement in August 2015, it took only one month to turn the agreement into operating HSR service in early September. The fast implementation of the Pingshan Express and then its further extension into the Shenshan Express can be attributed to a few factors.

First, travelers greatly prefer the operating speed of the HSR-based express compared to a metro line. For example, it only takes 21 minutes from Shenzhen North Station to Shenzhen Pingshan Station (Figure 4). The regular ticket price is $¥ 12$, cheaper than the planned metro service. By contrast, passenger trips by metro over this distance are much more time-consuming. It would take more than two hours to travel from Shenzhen North to Huizhou South station by metro, but it only takes half an hour by Shenshan HSR.

The headway of the Shenshan Express is not as dense as typical metro service. For now, it is about one hour (Figure 4). However, the introduction of the Shenshan Express sets an operating standard for other long-distance trains. A person with a train ticket from other stations to Shenzhen, can now board the first-available long-distance train, rather than the train specified on the ticket. This flexibility is, of course, subject to seat availability. As a result, the transit-style service actually has a much higher frequency than is suggested by Shenshan Express alone. 


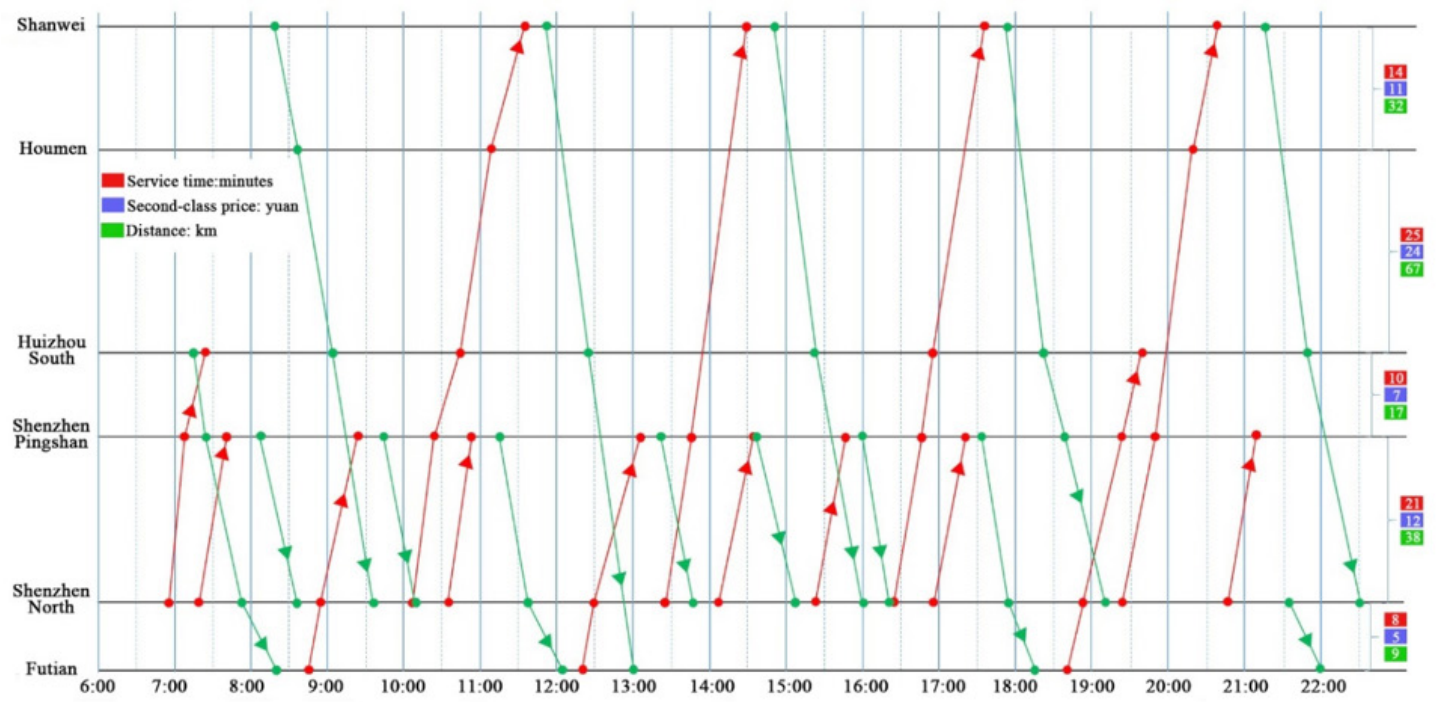

Figure 4: The operating schedule of Shenshan Express

Source: Compiled by authors based on data released on http://www.12306.cn. Accessed July 21, 2018.

Second, service purchase from Guangzhou Rail is a cost-saving solution for local governments. It is much cheaper than the two alternatives: metro or PRD intercity rail. In the case of a metro connection, the municipal governments would need to cover the engineering cost and then underwrite the operating deficit. If it were part of the PRD intercity rail network, the provincial and municipal governments would need to share the engineering cost and operating deficit. With purchased HSR service, the national government has already covered the engineering cost, the infrastructure is already constructed, and operational knowledge and capacity are in place. The city government only needs to finance the operating deficit.

Third, as the first case of HSR service purchased for metropolitan passenger transportation, the leadership of Guangdong provincial government and Shenzhen municipal government should be commended for their willingness to innovate in the enhancement of regional scale mobility. In China, innovation in the public sector relies on personal connections and the engagement of leadership at a relatively high level in the bureaucratic hierarchy, particularly considering that no formalized government guidance exists. Shenzhen government has obviously played a leading role in advancing the operation of the Pingshan Express and the Shenshan Express. The unique political resource brought by the municipal party secretary gives Shenzhen a huge bargaining power advantage when engaging with Guangzhou Rail for HSR service purchase. According to Interviewees No. 2 and No. 3, in June of 2015, MA spoke directly with the General Manager and Vice President of Guangzhou Rail, and the proposal to operate Pingshan Express was approved soon after.

Fourth, the willingness of other governments to compromise on sharing the operational deficit facilitated the deal. It was estimated that the Shenshan Express would operate at an annual loss of $¥ 180$ million. There was no widely accepted formula to split this deficit among relevant local governments (Interviewee No. 5). Fortunately, all local governments were willing to participate in negotiating a satisfactory compromise on this question. 


\section{$6 \quad$ Conclusions}

In metropolitan areas characterized by rapid growth, high population density, and buoyant economies, local governments must cooperate to supply fast, integrated, and high-capacity rail transit services. In particular, when industrial relocation and housing affordability lengthens commuting trips, a high-speed rail transit service becomes essential. By studying the transport investment actions in the SGHMA, this article reveals the potential for utilizing national HSR service for regional passenger mobility and the conditions that must be fulfilled.

First, the studied case demonstrates the feasibility of using national HSR infrastructure for metropolitan passenger mobility. Travelers benefit from saved trip time while local governments benefit from engineering cost savings and the knowledge of the national HSR team. The national HSR is better utilized as its excess capacity is now put to good use. The HSR-based regional transit in SGHMA serves as an alternative to inter-connected metro systems, which impose longer travel times on travelers, require a much higher cost subsidy from local governments, and are subject to greater uncertainty stemming from the vagaries of NDRC's approval process. In addition, the most recent update of the threshold values of GDP, fiscal revenue and population size will prevent a great number of cities from building their own metro systems. As a result, the popularity of HSR-based service is likely to increase.

Second, urbanized regions in China still lack a metropolitan planning organization (MPO) similar to the United States and Canada that is responsible for transportation investment and relevant policy arrangements. However, a variety of formal and informal institutional arrangements exist to plan, fund, and operate intercity infrastructure and services, which serve a role somewhat similar to that played by an MPO (Yang et al., 2015; Lin et al., 2015). The introduction of the Pingshan Express and then the Shenshan Express reflect some important institutional factors for utilizing HSR service for regional passenger mobility. These include 1) the bargaining power of the leading local government and 2) the coalition built by local governments to meet their common needs.

The successful operation of HSR for regional mobility is expected to have a considerable influence on individual housing choices and employment location selection, business location decisions, and local governments' land-use planning. As suggested by the existing literature, significant transit improvements can influence travel behavior, land value, and regional growth (e.g., Cervero \& Duncan 2002; Fan et al., 2012). As more examples of purchasing national HSR service develop in other corridors within the PRD and beyond, their implications and potential for economic development are waiting to be fully revealed.

\section{Acknowledgements}

This research is partly supported by National Natural Science Foundation of China (51678004), the Guangdong Province Research Grant 2016A020223016, the Lincoln Institute of Land Policy, the Junior Fellowships of CAST Advanced S\&T Think-tank Program (DXB-ZKQN-2017-019), and the Natural Science Foundation of Zhejiang Province (LQ19D010003). 


\section{References}

Armstrong, R. J., \& Rodríguez, D. A. (2006). An evaluation of the accessibility benefits of commuter rail in Eastern Massachusetts using spatial hedonic price functions. Transportation, 33(1), 21-43. doi: $10.1007 / s 11116-005-0949-x$

Bendibao. (2016, September). The operation of Shenzhen-Huizhou-Shanwei intercity HSR has been scheduled. Retrieved from http://jt.sz.bendibao.com/news/2016921/781369.htm

Cervero, R., \& Duncan. M. (2002). Transit's value-added effects: Light and commuter rail services and commercial land values. Transportation Research Record, 1805, 8-15. doi: org/10.3141/1805-02

Cervero, R. (2013). Linking urban transport and land use in developing countries. Journal of Transport and Land Use, 6(1), 7-24. doi: 10.5198/jtlu.v6i1.425

Charles, M. B., Ryan, N., \& Kivits, R. A. (2012). Moving towards sustainable intercity transport: A case study of high-speed rail in Australia. International Journal of Sustainable Development, 15, 125-147. doi: 10.1504/IJSD.2012.044038

China Association of Metros. (2018). Overview of urban rail transit in mainland China in 2017. China Metros, 1, 16-21. doi: 10.14052/j.cnki.china.metros.2018.01.004

Diao, M., Zhu, Y., \& Zhu, J. (2017). Intra-city access to intercity transport nodes: The implications of high-speed-rail station locations for the urban development of Chinese cities. Urban Studies, 54(10), 2249-2267. doi: 10.1177/0042098016646686

Didi Chuxing. (2017-May). The scale of intercity commuting in the Greater Pearl River Delta was triple than that in 2016. Retrieved from http://static.nfapp.southcn.com/content/201705/11/c418557. html

Deka, D. (2012). The impacts of non-resident parking restrictions at commuter rail stations. Journal of Transport Geography, 24, 451-461. doi: 10.1016/j.jtrangeo.2012.05.004

Dongguan Daily. (2012-May). Considerable benefits of intercity cooperation within Shenzhen-Dongguan-Huizhou metropolitan area. Retrieved from http://epaper.timedg.com/html/2012-05/17/content_967755.htm

Dongguan Daily. (2013-Aug.). A global industrial base was planned in Shenzhen-Dongguan-Huizhou metropolitan area. Retrieved from http://epaper.timedg.com/html/2013-08/08/content_1204983. htm

Fan, Y., Guthrie, A., \& Levinson, D. (2012). Impact of light rail implementation on regional labor market accessibility: A transportation equity perspective. Journal of Transport and Land Use, 5(3), 28-39. doi: 10.5198/jtlu.v5i3.240

Guangdong Government. (2008). Guangdong Government's outline for the reform and development of the Pearl River Delta, 2008. Guangzhou, Guangdong Province: Guangdong Government.

Guangdong Government. (2005). The intercity rail transit network plan of the Pearl River Delta (20052020). Guangzhou, Guangdong Province: Guangdong Government.

Geloso, V. (2012). Intercity bus services in Canada: Time for deregulation. Economic Affairs, 32(1), 38-42. doi: 10.1111/j.1468-0270.2011.02126.x

Huizhou News. (2016-Sept.). 70\% of the industrial projects recently settled in Huiyang District of Huizhou come from Shenzhen. Retrieved from http://e.hznews.com/paper/djsb/20160909/A03/2/.

Li, G., Luan, X., Yang, J., \& Lin, X. (2013). Value capture beyond municipalities: Transit-oriented development and intercity passenger rail investment in China's Pearl River Delta. Journal of Transport Geography, 33, 268-277. doi: 10.1016/j.jtrangeo.2013.08.015

Li, S., Liu, X., Li, Z., Wu, Z., Yan, Z., Chen Y., \& Gao, F. (2018). Spatial and temporal dynamics of urban expansion along the Guangzhou-Foshan intercity rail transit corridor, China. Sustainability, 10(3), 593-621. doi: 10.3390/su10030593 
Lin, X., Yang, J., \& Wang, F. (2017). Facilitating intercity rail transit metropolis by extending city metro systems. Urban Rapid Rail Transit, 30(4), 1-7. doi: 10.3969/j.issn.1672-6073.2017.04.001

Lin, X., Yang, J., \& Sun, D. (2015). Metropolitan inter-jurisdictional public transportation and spatial coordinated development: Theory, cases, and reflections. Economic Geography, 35(9), 40-48. (In Chinese) doi: 10.15957/j.cnki.jjdl.2015.09.006

Mu, R., de Jong, M., Ma, Y., \& Xi, B. (2015). Trading off public values in high-speed rail development in China. Journal of Transport Geography, 43, 66-77. doi: 10.1016/j.jtrangeo.2015.01.010

Sina News. (2018-April). The announcement on the station location of Shenzhen Metro line 14 (Pingshan section). Retrieved from http://shenzhen.sina.com.cn/news/s/2018-04-18/detail-ifzihnep2438011.shtml?from=shenzhen_cnxh

Sperry, B., Ball, K., \& Morgan, C. (2011). Cluster analysis of intercity rail passengers in emerging highspeed rail corridor. Transportation Research Record, 2261,31-38. doi: 10.3141/2261-04

State Council of China. (2003). Regulation on construction and management of city rail transit in China (2003). Beijing: State Council of China.

State Council of China. (2005-March). The State Council's approval on the intercity rail transport network plan in the Capital Economic Zone, Yangtze River Delta, and Pearl River Delta. Retrieved from: http://www.gov.cn/ztzl/2006-07/01/content_324546.htm

State Council of China. (2018). Updated regulation on planning, construction, and management of city rail transit in China. Beijing: State Council of China.

Tencent News. (2016-March). More than $60 \%$ of the respondents consider buying a housing outside Shenzhen. Retrieved from http://sz.house.qq.com/a/20160303/001991.htm

Wang, J., Rong, C., Xu, J., \& Sui, W. O. (2012). The funding of hierarchical railway development in China. Research in Transportation Economics, 35(1), 26-33. doi: 10.1016/j.retrec.2011.11.004

Wang, R. (2011). Autos, transit and bicycles: Comparing the costs in large Chinese cities. Transport Policy, 18(1), 139-146. doi: 10.1016/j.tranpol.2010.07.003

Xu, J., \& Yeh, A. G. O. (2013). Interjurisdictional cooperation through bargaining: The case of the Guangzhou-Zhuhai railway in the Pearl River Delta, China. China Quarterly, 213, 130-151. doi: $10.1017 /$ S0305741013000283

$\mathrm{Xu}, \mathrm{J}$. (2017). Contentious space and scale politics: Planning for intercity railway in China's mega-city regions. Asia Pacific Viewpoint, 58(1), 57-73. doi: 10.1111/apv.12142

Yang, J., Lin, X., \& Xie, Y. (2015). Intercity transportation planning in China: Case of the GuangzhouFoshan metropolitan area. Transportation Research Record, 2512, 73-80. doi: 10.3141/2512-09

Yang, J., Chen, J., Le, X., \& Zhang, Q. (2016). Density-oriented versus development-oriented transit investment: Decoding metro station location selection in Shenzhen. Transport Policy, 51, 93-102. doi: $10.1016 /$ j.tranpol.2016.04.004

Zhou, J. (2016). The transit metropolis of Chinese characteristics? Literature review, interviews, surveys and case studies. Transport Policy, 51, 115-125. doi: 10.1016/j.tranpol.2015.11.009 